\title{
A Classification of Mathematical Modeling Problems of Prospective Mathematics Teachers
}

\author{
Alattin Ural (Corresponding author) \\ Mehmet Akif Ersoy University, Turkey \\ E-mail: ural@mehmetakif.edu.tr
}

Received: February 26, 2020

Accepted: March 31, 2020 Published: April 10, 2020

doi:10.5296/jei.v6i1.16566

URL: https://doi.org/10.5296/jei.v6i1.16566

\begin{abstract}
The purpose of this research is to classify the mathematical modelling problems produced by pre-service mathematics teachers in terms of the number of variables and to determine the mathematical modelling skills and mathematical skills used in solving the problems in each class. The current study is a qualitative research and the data was analyzed using descriptive analysis. The data of the study was obtained from the mathematical modelling problem written by 59 senior mathematics teachers. They were given a 1-week period to write the problems and solutions. The participants took mathematical modelling course for one semester period prior to the research. The problems are the original problems that the participants themselves produced. The mathematical modelling problems produced are categorically as follows: "Which option is more economical" problems, "Profit-making" problems, "Future prediction" problems and "Relationship between two quantities" problems. The mathematical modelling skills used are as follows: to be able to collect appropriate data, organize the data, write dependent and independent variables, write fixed values, visualize the real situation mathematically or geometrically, use mathematical concepts. The mathematical skills used are generally; to be able to do four operations with rational numbers, draw distribution and column graph, write algebraic expression, do arithmetic operation in algebraic rational expressions, write/solve equation and inequality in 1 or 2 variables, write an appropriate mathematical function explaining the data related to the data, solve 1st degree equations in 1 variable, establish proportion, use trigonometric ratios in right triangle, use basic geometry information, draw and interpret a 1 st degree inequality in 2 variables.
\end{abstract}

Keywords: Mathematical modelling, Mathematical modelling problems, Mathematics teacher candidate 


\section{MIN Macrothink}

\section{Introduction}

Mathematical modelling problems are non-routine problem situations that express complex real-life situations and contain different possible solutions. The first step in the mathematical modeling process is to understand the real-life problem. Here the person defines the problem, collects and analyses the appropriate data. The next stage is the stage of choosing the variables necessary to solve this problem. After this stage, the necessary mathematical works are done and a mathematical model is created, its accuracy and suitability are investigated. The solution obtained is interpreted in real life. At the last stage, the model is developed and generalized for other problems (Berry \& Houston, 1995).

Mathematical modeling is linked to other mathematical skills such as mathematical reading-understanding, thinking and applying problem solving strategies, reasoning, calculation, etc. (Niss, 2003). Several studies have shown that students have difficulties in handling real-life situations that require a mathematical solution (Christiansen, 2001; Crouch \& Haines, 2004; Haines, Crouch, \& Davies, 2001; Ikeda \& Stephens, 2001; Klymchuk \& Zverkova, 2001). Niss (2001) stated that the performance of students in the modeling process may be affected by the teaching approach, the problem situation given in terms of the interest of the student, the motivation of the teacher and themselves, the effort shown and their previous experiences. Galbraith and Stillman (2001) stated that students' general knowledge about the situation in the context also affects their modeling skills. In their studies in nine countries, Klymchuk and Zverkova (2001) revealed that students found difficult to switch between the real world and the mathematical world because they had not experienced such practices before. Tanner and Jones (1995) observed that knowledge alone was not sufficient for successful modeling, students should know what knowledge to use where, and at this point he observed that the students had difficulty. In the study conducted by Erdoğan (2010), it was revealed that students had significant difficulties in using the concept of function while solving modeling problems.

Mathematical modelling problems can be grouped under two main headings; theoretical and experimental modelling. While theoretical modelling includes mathematical, statistical and computer-based information, in experimental modelling, the solution of mathematical modelling is asked by giving information about experiment, observation and their results (Berry \& Houston, 1995; Kapur, 1982).

Blum (1991) revealed the table below regarding real-world examples and related mathematical topics. 
Table 1. Real-world examples and related mathematical topics

\begin{tabular}{|l|l|}
\hline Real-world examples & Related mathematical topics \\
\hline $\begin{array}{l}\text { various growth and decay processes: population growth, } \\
\text { chemical reactions, spread of epidemics, warming/cooling, } \\
\text { absorption, decay of beer froth and so on }\end{array}$ & functions, calculus, linear, algebra \\
\hline rainbow & geometry, calculus \\
\hline genetics & arithmetic, probability, (linear) \\
\hline rates of interest & algebra \\
\hline price index & arithmetic, functions, calculus \\
\hline income tax & arithmetic, algebra, functions \\
\hline elections & arithmetic, functions, calculus \\
\hline social classes & arithmetic, geometry, stochastic \\
\hline traffic flow & finite maths, probability, linear \\
\hline biking & algebra \\
\hline chairoplane & linear algebra, functions, calculus \\
\hline gambling & stochastics, finite maths \\
\hline painting & geometry, algebra \\
\hline musical scales & arithmetic, algebra, functions \\
\hline
\end{tabular}

Solving mathematical modelling problems is related to one's mathematical modelling competence. According to Blum (1996), mathematical modelling competencies are those:

- Competence to understand real life problems and create a real model;

- Competence to create a mathematical model from real life model;

- Competence to solve mathematical problems in the mathematical model;

- Competence to interpret mathematical results for real life;

- Competence to question the solution and perform another modelling process if necessary.

Jensen (2007) stated three dimensions to assess someone's possession of a competency: Degree of coverage indicating which aspects of the competency someone can activate and the degree of autonomy with which this activation takes place. Radius of action, indicating the spectrum of contexts and situations in which someone can activate the competency. Technical level, indicating how conceptually and technically advanced the mathematics is that someone can integrate relevantly in activating the competency. The radius of action addresses the domain of situations in which someone can perform mathematical modelling activities. For example, the fact that someone is very competent when it comes to developing and using 


\section{Macrothink}

optimization models in everyday shopping situations, for example, does not guarantee the same competence when it comes to design problems. The technical level addresses which kind of mathematics someone can use and how flexible they are in their use of mathematics. These three dimensions have been visualized geometrically in Figure 1. In this model the possession of a competence is represented by a volume. We need to pay attention to all the dimensions when we attempt to support the development of a competence, for example, mathematical modelling competency, among a group of students.

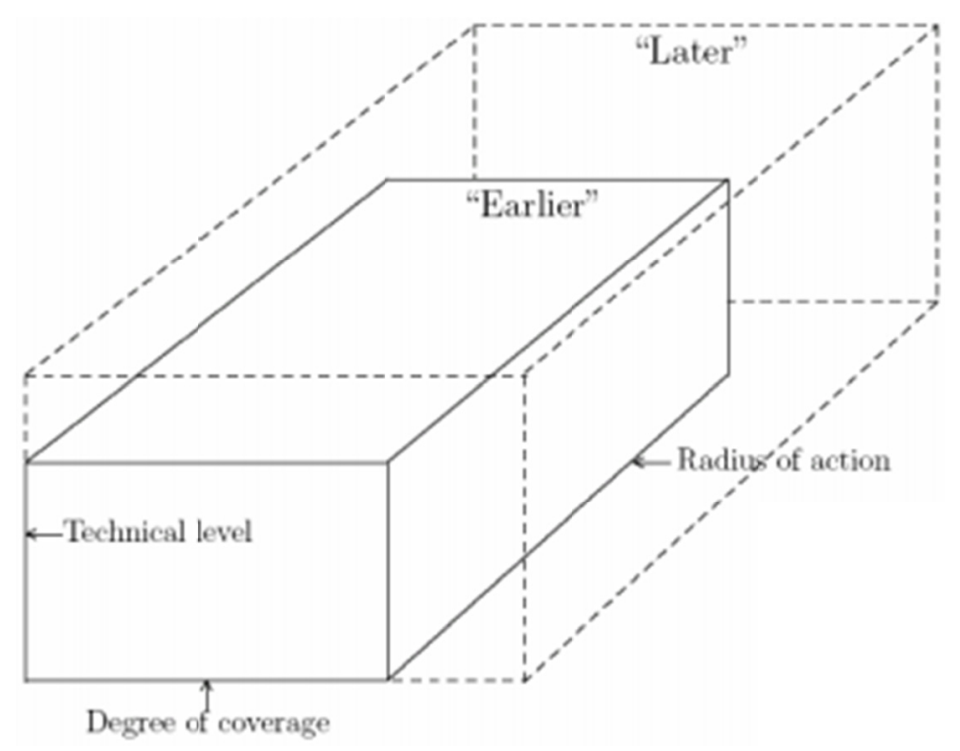

Figure 1. Geometrically visualized three dimensions (degree of coverage, radius of action, and technical level)

Most of the mathematical modeling researches in mathematics education is about the modeling competencies of the participants, the difficulties they face and the effect of the mathematical modeling education on students' conceptual development in mathematics. No research has been found in the literature regarding the classification of mathematical modeling problems produced by students. In this study, it is focused on classifying the mathematical models, problems and mathematical modelling skills produced by the participants in a holistic way. Thus, a contribution will be made to the literature in terms of this gap. In addition, it is thought that the results obtained from the current research will contribute to the process of development of the mathematical modelling education.

\section{Methods}

The purpose of this research is to classify the mathematical modelling problems produced by pre-service mathematics teachers in terms of the number of variables and to determine the mathematical modelling skills and mathematical skills used in solving the problems in each class. The current study is a qualitative research and the data was analysed using descriptive analysis. The data of the study was obtained from the mathematical modelling problem 
written by 59 mathematics teacher candidates. The participants were the $4^{\text {th }}$ grade students at the Mathematics Teacher Training Programme of Faculty of Education. The participants took mathematical modelling course for one semester period before the research. They were given a 1-week period to write the problems and solutions. The problems are the original problems that the participants themselves produced. The problems were first classified in terms of the number of variables used in mathematical models. Then, the mathematical models in each class were examined in terms of the mathematics topics and mathematical modelling skills used.

\section{Findings}

A classification of mathematical models produced by prospective mathematics teachers based on the number of variables used is given below. Each class consists of three sub-categories: type of the mathematical modelling problems, mathematical modelling skills and mathematical skills.

\subsection{Non-variable Solutions (Level 0)}

Preservice teachers in this category created a solution without using variables in the solution of real life problems they produced. However, the solution of such problems depends on some conditions and requires variable use. Pre-service teachers did not use variables by collecting some data and taking some average values based on these data. Therefore, they were unable to put forward a mathematical model.

\subsubsection{Problem Types}

The categories created regarding the content of the modelling problems produced by the participants are as follows:

- The problems of "which option is more economical": in such problems, the participants tried to find out which of the two options would be more economical. The problem titles they used are as follows: "carboy or water purifier", "farm for meat or milk", "bus or car (for 4-year university term)", "rent or buy".

- The problems of "earning money": "at least how many ratings should a series take to earn money", "earning status of a flower greenhouse", "parking prices.".

\subsubsection{Mathematical Modelling Skills Used}

Gathering appropriate data, organizing data, mathematical skills.

\subsubsection{Mathematical Skills Used}

4 operations with rational numbers, distribution and column chart.

\subsection{One Variable Mathematical Models (Level 1)}

\subsubsection{Problem Types}

The categories created regarding the content of the 1-variable modelling problems are as follows: 


\section{Macrothink}

- The problems of which option is more economical: In such problems, the participants examined the conditions for which of the two options would be more economical. The problem titles they use are as follows: "rechargeable or battery-operated", "carboy water or water purifier", "anti-lime tablet or magnetic anti-lime for dishwasher", "bus or car (for 4-year university term)", "drip or normal irrigation".

- The problems of prediction of future: The participants tried to present a mathematical model in such problems in order to make predictions about a quantity that changes depending on time. The problem titles they used are as follows: "maximum hair length", "when does the lake dry", "use rate of recycling".

- The problems of profit-making: In such problems, the participants examined the conditions for a job to be profitable. The problem titles used are as follows: "How many passengers should be at least for gain", "At least how many kilograms of bananas should be produced to make money", "Sun panel", "Minimum advertising cost".

- The problems of relationship between two quantities: The participants investigated the mathematical relationship between two quantities in such problems. The problem titles they used are as follows: "Relationship between distance and height", "Relationship between number of tourists and income", "Relationship between population and time", "Weight loss", "How much fuel is there in the fuel tank".

\subsubsection{Mathematical Modeling Skills Used}

To be able to gather appropriate data, organize the data, to be able to write dependent and independent variables, write constant values, convert the real problem to mathematical problem, interpret the model in terms of real life, visualize the real situation mathematically and use the needed mathematical concepts in the process of solution.

\subsubsection{Mathematical Skills Used}

In addition to the mathematical skills in 3.1.3, to be able to write algebraic expression, make arithmetic operations with algebraic rational expressions, establish and solve 1st degree 1 unknown equation or inequality, write the most appropriate mathematical function regarding the data (such as 2nd degree polynomial, exponential function), solve 2nd degree 1-variable equation, establish proportion, use trigonometric ratios in the right triangle, use the basic geometry knowledge.

\subsection{Two Variable Mathematical Models (Level 2)}

\subsubsection{Problem Types}

The categories created regarding the content of the 2-variable modelling problems are as follows:

- The problems of which option is more economical: "stone block pavement or asphalt", "Carboy water or water purifier", "4 season tire or winter and summer tire separately", "Making pomegranate sour at home or buying", "Which fleet rental company", "Bus or car (for 4-year university term)", "Rent or buy a fleet". 


\section{Macrothink}

- The problems of profit-making: The problem titles used are as follows: "Minimum advertising cost", "3rd bridge: how many years to recover", "Should he go to the remote station for cheap fuel", "At least how many years later does jacketing amortise itself", "How many tables and chairs must be produced to make the gain the most", "How many years later does a dishwasher amortise itself", "At least how many students should live that a dormitory make money", "What types of components should be mixed into two types of coffee to make maximum weekly earnings", "Production of tahini-molasses at minimum cost", "when does a solar panel recover itself", "when does the capital recover itself'.

\subsubsection{Mathematical Modeling Skills Used}

To be able to gather appropriate data, organize the data, to be able to write dependent and independent variables, write constant values, convert the real problem to mathematical problem, interpret the model in terms of real life, visualize the real situation mathematically and use the needed mathematical concepts in the process of solution.

\subsubsection{Mathematical Skills Used}

In addition to the mathematical skills in 3.2 .3 , to be able to write 2 variable algebraic expressions, establish 1st degree 2 unknown inequality, draw and interpret a graph of 1st degree 2 unknown inequality, use special defined functions (such as absolute value, exact value).

\subsection{Multivariate Mathematical Models}

\subsubsection{Problem Types}

The categories created regarding the content of the multivariate modelling problems are as follows:

- The problems of which option is more economical: "Normal cigarette or electronic cigarette", "Homemade tomato paste production".

- The problems of relationship between two quantities: "Relationship between packaging and price".

- The problems of profit-making: "Water vendor's gain function", "Cost function of diet", "Maximum profit", "Saving the cost of jacketing", "Production of cleaning materials to meet the demand at minimum cost", "Under what conditions buying a room thermostat would be more economical", "How many pieces of clothing should be produced per week in order to make the most profit", "profit-making status of a company giving the driving license courses", "Obtaining the most profit with minimum cost", "Which foods should be on the breakfast plate for a child with minimum cost".

\subsubsection{Mathematical Modeling Skills Used}

To be able to gather appropriate data, organize the data, to be able to write dependent and independent variables, write constant values, convert the real problem to mathematical 


\section{Macrothink}

problem, the needed mathematical concepts in the process of solution.

\subsubsection{Mathematical Skills Used}

To be able to do arithmetic operations in rational numbers, write algebraic expression, do arithmetic operations with algebraic and rational expressions, write max three variable linear inequality system (aim function),

\section{Results}

When looked at the models of mathematics teacher candidates; it was seen that $16 \%$ of them had no variable (only arithmetic operations); $31 \%$ of them had 1 -variable, $31 \%$ of them had 2 -variable and $22 \%$ of them were multivariate.

The problems produced by the participants are presented categorically in the Table 2 .

Table 2. The Themes of the Problems

\begin{tabular}{|l|l|l|l|l|l|}
\hline The theme of the problem & $\begin{array}{l}\text { Non-variable } \\
\text { Solutions }\end{array}$ & $\begin{array}{l}\text { 1-variable } \\
\text { Models }\end{array}$ & $\begin{array}{l}\text { 2-variable } \\
\text { Models }\end{array}$ & $\begin{array}{l}\text { Multivariate } \\
\text { Models }\end{array}$ & Total \\
\hline Profit-making & 5 & 4 & 10 & 9 & 28 \\
\hline Which option is more profitable & 5 & 5 & 8 & 3 & 21 \\
\hline Relationship between two quantities & & 5 & & $\mathbb{1}$ & 6 \\
\hline Future prediction & & 4 & & & 4 \\
\hline Total & 10 & 18 & 18 & $\mathbb{1 1}$ & 59 \\
\hline
\end{tabular}

When the table is analyzed, it is seen that the problems of "Which option is more economical" and "Profit elimination" are a common problem type in each category.

The results regarding mathematics topics and mathematical modelling abilities on the basis of number of variables are shown generally in Table 3. 


\section{$\triangle$ Macrothink}

Table 3. Mathematics topics and mathematical modelling abilities on the basis of number of variables

\begin{tabular}{|l|l|l|}
\hline $\begin{array}{l}\text { Number of } \\
\text { Variables }\end{array}$ & Mathematics Topics & Mathematical Modelling Abilities \\
\hline 0 & Four operation in Q, distribution and column graph & To collect appropriate data, organize the data \\
\hline 1 & $\begin{array}{l}\text { (Level 0+) 1st degree 1 unknown algebraic expressions } \\
\text { and } 4 \text { operations, rational expressions, 1st degree 1 } \\
\text { unknown equation or inequality, basic knowledge of } \\
\text { function such as 2nd degree polynomial, exponential } \\
\text { function and graph of them, solution of 2nd degree } \\
\text { 1-variable equation, ratio-proportion, basic knowledge } \\
\text { of geometry and trigonometry in the right triangle }\end{array}$ & $\begin{array}{l}\text { (Level 0+) to be able to write dependent and } \\
\text { visualize the real situation mathematically, } \\
\text { convert the real problem to mathematical } \\
\text { problem, solve the mathematical problem, } \\
\text { interpret the model }\end{array}$ \\
\hline 2 & $\begin{array}{l}\text { (Level 1+) 1st degree 2-variable algebraic expressions, } \\
\text { 1st degree 2 unknown inequality and graph of it, } \\
\text { absolute value and exact value functions }\end{array}$ & $\begin{array}{l}\text { (Level 1+) to determine some restricts of the } \\
\text { model }\end{array}$ \\
\hline Min 3 & $\begin{array}{l}\text { (Level 0+) 4 operations with algebraic and rational } \\
\text { expressions, linear inequality system }\end{array}$ & \\
\hline
\end{tabular}

When the table is examined; mathematical modeling skills can be leveled as follows: Level-0 (Non-variable models), Level-1 (1-variable models), Level-2 (min 2-variable models). On the other hand, it is seen that mathematical skills (math topics) are leveled as Level-0 (Non-variable models), Level-1 (1-variable models) and Level-2 (2-variable models). As known, mathematical modeling skills include mathematical skills, so these two results should be considered together. Therefore, on the basis of the findings of this research; mathematical modeling skills are leveled as follows: Level-0 (Non-variable models), Level-1 (1-variable models) and Level-2 (2-variable models).

When the solutions of the participants were examined; as the number of variables included in the model increased from 0 to 2 , it was seen that the mathematical subjects and mathematical modelling skills used by the participants increased in the manner that cover the previous level. Therefore, the number of variables in the model also shows the level of mathematical modelling skill. However, considering that the models with 3 or more variables are generally limited to writing a gain/aim function (inequality system with 1 degree); it cannot be said that the mathematical subjects and mathematical modelling skills used in this category are more than level 2. Therefore, it would be appropriate to evaluate this category within level 2. A typical example of mathematical modelling using a minimum of 3 variables was presented below:

The Company wants the total risk not to exceed 0.12 as per its investment policy. In addition, the amount of profit he plans to make from this investment is at least 25,000 TL. In addition, he wishes to buy at least 50,000 TL shares from the Company 3, which he thinks may establish a partnership in the future. According to the above data, let's create a model that will 
maximize the profit of the company.

$X_{1}=$ stock of the company $1\left(H S_{1}\right)$

$X_{2}=$ stock of the company $2\left(H S_{2}\right)$

$X_{3}=$ stock of the company $3\left(H S_{3}\right)$

$X_{4}=$ stock of the company $4\left(H S_{4}\right)$

$X_{5}=$ stock of the company $5\left(H S_{5}\right)$

Gain Function: $Z=0.23 X_{1}+0.16 X_{2}+0.04 X_{3}+0.08 X_{4}+0.28 X_{5}$

Restrictions:

$X_{1}+X_{2}+X_{3}+X_{4}+X_{5} \leq 250.000$ (capital restriction)

$\frac{X_{1.0,15}+X_{2.0,12}+X_{3.0,03}+X_{4.0,05}+X_{5.0,18}}{X_{1}+X_{2}+X_{3}+X_{4}+X_{5}} \leq 0.12$ (risk restriction)

$Z=0.23 X_{1}+0.16 X_{2}+0.04 X_{3}+0.08 X_{4}+0.28 X_{5} \geq 25.000$ (profit restriction)

$X_{3} \geq 50.000$ (restriction of the company 3 )

$X_{1}, X_{2}, X_{3}, X_{4}, X_{5} \geq 0$

\section{Discussion and Conclusion}

The problems produced by the participants are thematically as follows: the problems of profit-making, which option is more profitable, relationship between two quantities, prediction of future. The mathematical topics involved in the solution of the mathematical modelling problems are those: algebraic expressions, rational expressions, 1st degree equations or inequality in 1 or 2 unknown, column or line graph, linear or exponential function, 2nd degree polynomial, 2nd degree equation in 1 unknown, ratio-proportion, trigonometric ratios in orthogonal triangle and Pythagorean relation. Mathematical modelling skills used by the participants in the mathematical modelling process are as follows: to distinguish between dependent and independent variables, to collect appropriate data, to make assumptions, to write constant values, to use the mathematical concepts and operations in the mathematical solution stage, to visualize the real situation mathematically or geometrically, to interpret the model.

Another result obtained from the study is that as the number of variables included in the model increased from 0 to 2 , it was seen that the mathematical subjects and mathematical modelling skills used by the participants increased in the manner that cover the previous level. Therefore, it can be said that the number of variables in the model also shows the level of mathematical modelling skills.

When considered the mathematics subjects that mathematics teacher candidates learned during their education life; it was seen that the solutions they presented in the process of mathematical modelling were the mathematical concepts and skills at most at high school level (most of them are at the level of middle school). As known, in the process of traditional teaching, students learn the mathematical concepts in a procedural way and do not learn how to use mathematical concepts in which contexts. This result can be stemmed from this situation. 
Another important point in this context is that $12 \%$ of pre-service mathematics teachers made solutions by using only arithmetic operations without using variables (algebra). The fact that pre-service mathematics teachers who should have acquired the subjects of the secondary school curriculum such as variable, algebraic expression, equation, inequality were not be able to use these concepts is also another finding. Similar findings were found in a study by Ural (2020). If students are required to set mathematical modelling at a good level, the use of mathematical concepts in real life problems should be emphasized, at least from middle school.

Blum (1991) revealed a table regarding real-world examples and related mathematical topics (Table 1). It was seen that the problems of "growth process" and "price index" which are among the real-life problems in this table, are also included in the current research. Differently, in the current study, "profit-making" and "relationship between two quantities" themed problems are included. In terms of mathematics topics; functions, algebra, geometry and arithmetic were also included in the current research. Differently, in this study, the subject of trigonometry was used in a few problems.

The duration, content and teaching method of mathematical modeling education, which was given 1 hour a week, through one semester, is a significant limitation of the research as an important factor of the mathematical modeling problems that students produced and the modeling process they did. The content of the courses consisted of the book "Matematiksel Modelleme Eğitimi (Mathematical Modeling Education)" written by Ural (2018). Modeling activities in the book require mathematical knowledge and skills at the secondary and high school levels. Therefore, a change in these factors may affect obtaining different results. Considering that the participants were senior students of the mathematics teaching department and received sufficient mathematical modeling education; it can be stated that there is no significant limitation for the participants. For future studies, at the end of a longer-term mathematical modeling education required by higher mathematical knowledge and skills, students may be asked to produce and solve mathematical modeling problems. Thus, the types of problems produced and the mathematical skills may differ.

\section{References}

Berry, J., \& Houston, K. (1995). Mathematical modelling. Bristol: J. W. Arrowsmith Ltd.

Blum, W. (1991). Applications and Modelling in Mathematics Teaching: A Review of Arguments and Instructional Aspects. In M. Niss, W. Blum \& I. Huntley (Eds.), Teaching of mathematical modelling and applications (pp. 10-29). Ellis Horwood Limited, Chichester, England.

Blum, W. (1996). Anwendungsbezüge im Mathematikunterricht. Trends und Perspektiven. Schriftenreihe Didaktik der Mathematik, 23, 15-38.

Christiansen, I. (2001). The effect of task organisation on classroom modelling activities. In J. Matos, W. Blum, K. Houston, \& S. Carreira (Eds.), Modelling and mathematics education, ICTMA 9: Applications in science and technology (pp. 311-320). Chichester: Horwood Publishing. https://doi.org/10.1533/9780857099655.5.311 


\section{Macrothink}

Crouch, R., \& Haines, C. (2004). Mathematical modelling: Transitions between the real world and the mathematical model. Int. J. Math. Educ. Sci. Technol., 35(2), 197-206. https://doi.org/10.1080/00207390310001638322

Erdoğan, A. (2010). Primary teacher education students'ability to use functions as modeling tools. Procedia Social and Behavioral Sciences, 2, 4518-4522. https://doi.org/10.1016/ j.sbspro.2010.03.723

Galbraith, P., \& Stillman, G. (2001). In J. F. Matos, W. Blum, S. K. Houston, \& S. P. Carreira (Eds.), Modelling and Mathematics. Chichester: Horwood Publishing.

Haines, C., Crouch, R., \& Davies, J. (2001). Understanding students' modelling skills. In J. Matos, W. Blum, K. Houston, \& S. Carreira (Eds.), Modelling and mathematics education, ICTMA 9: Applications in science and technology (pp. 366-380). Chichester: Horwood Publishing. https://doi.org/10.1533/9780857099655.5.366

Ikeda, T., \& Stephens, M. (2001). The effects of students'discussion in mathematical modelling. In J. F. Matos, W. Blum, S. K. Houston, \& S. P. Carreira (Eds.), Modelling and mathematics education (pp. 381-400). Chichester: Horwood Publishing. https://doi.org/ 10.1533/9780857099655.5.381

Jensen, T. H. (2007). Assessing mathematical modellibg competency. In C. Haines, P. Galbraith, W. Blum, \& S. Khan (Eds.), Mathematical Modelling (ICTMA12) Education, Engineering and Economics. Chichester: Horwood.

Kapur, J. N. (1982). The art of teaching the art of mathematical modelling. International Journal of Mathematical Education in Science and Technology, 13(2), 185-192. https://doi.org/10.1080/0020739820130210

Klymchuk, S., \& Zverkova, T. (2001). In J. F. Matos, W. Blum, S. K. Houston, \& S. P. Carriera (Eds.), Modelling and mathematics education (p. 227). Chichester: Horwood Publishing. https://doi.org/10.1533/9780857099655.4.227

Niss, M. (2001). University mathematics based on problem-oriented student projects: 25 years of experiences with the Roskilde model. In D. Holton (Ed.), The teaching and learning of mathematics at university level: an ICMI study (pp. 405-422). Dordrecht: Kluwer Academic Publishers.

Niss, M. (2003). Mathematical competencies and the learning of mathematics: The Danish KOM Project. In A. P. Gagatsis (Eds.), 3rd Mediterranean Conference on Mathematical Education (pp. 115-124). Athens: The Hellenic Mathematical Society.

Tanner, H., \& Jones, S. (1995). Developing metacognitive skills in mathematical modelling-A socio-contructivist interpretation. In C. Sloyer, W. Blum, \& I. Huntley, (Eds.), Advances and perspectives in the teaching of mathematical modelling and applications (pp. 61-70). Yorklyn: Water Street Mathematics.

Ural, A. (2018). Matematiksel Modelleme Ĕ̈itimi. Ankara: Anı Publishing. 


\section{Macrothink

Ural, A. (2020). A comparative study of mathematical modelling competences between English and Turkish undergraduate mathematics students. European Journal of Education Studies, 6(10).

\section{Copyright Disclaimer}

Copyright for this article is retained by the author(s), with first publication rights granted to the journal.

This is an open-access article distributed under the terms and conditions of the Creative Commons Attribution license (http://creativecommons.org/licenses/by/3.0/). 